\title{
Camel milk consumption is associated with less childhood stunting and underweight than bovine milk in rural pastoral districts of Somali, Ethiopia: a cross-sectional study
}

\author{
Anbissa Muleta ${ }^{1,2}$ (D), Dejene Hailu ${ }^{3}$, Barbara J. Stoecker ${ }^{4}$ and Tefera Belachew ${ }^{5}$ \\ ${ }^{1}$ Department of Food Science and Nutrition, Jigiga University, Jigjiga, Ethiopia \\ ${ }^{2}$ School of Nutrition, Food Science and Technology, Hawassa University, Hawassa, Ethiopia \\ ${ }^{3}$ Department of Public and Environmental Health, College of Health Sciences, Hawassa University, Hawassa, Ethiopia \\ ${ }^{4}$ Department of Nutritional Sciences, Oklahoma State University, Stillwater, OK, USA \\ ${ }^{5}$ Department of Nutrition and Dietetics, Jimma University, Jimma, Ethiopia
}

(Received 21 March 2021 - Final revision received 18 July 2021 - Accepted 24 August 2021)

Journal of Nutritional Science (2021), vol. 10, e78, page 1 of 8

doi:10.1017/jns.2021.75

\section{Abstract}

Undernutrition is a major global health problem. Various types of animal milk are used for feeding children at early ages; however, associations of camel milk (CaM) and bovine milk (BM) with the nutritional status of children have not been explored. A comparative community-based cross-sectional study was conducted among pre-schoolers in rural pastoral districts of Somali, Ethiopia. Children were selected from households with lactating camels or cows. Anthropometric measurements followed standard procedures for height-for-age, weight-for-age and weight-for-height scores. Independent sample $t$-tests identified significant differences in anthropometric indices based on the type of milk consumed. Multivariable logistic regression was used to examine associations between milk consumption and other predictors of growth failures. The prevalence of stunting was $24 \cdot 1 \%$ [95 \% confidence interval (CI) $20 \cdot 5$, 28.3] of pre-schoolers, 34.8 \% (95\% CI 29.9, 39.6) were wasted and 34.7\% (95\% CI 30·1, 39.9) were underweight. Higher proportions of BM-fed children were severely stunted, wasted and underweight compared with CaM consumers. Using logistic regression models, children who consumed BM [adjusted odds ratio (AOR): 2.10; $95 \%$ CI 1.22, 3.61] and who were anaemic (AOR: 4.22; $95 \%$ CI 2.23, 7.98) were more likely to be stunted than their counterparts, while girls were less likely to be stunted than boys (AOR: 0.57; $95 \%$ CI 0.34, 0.94). Similarly, children who consumed BM (AOR: 1.97; $95 \%$ CI 1.20, 3.24), who were anaemic (AOR: 2.27; $95 \%$ CI 1.38, 3.72) and who drank unsafe water (AOR: 1.91; 95\% CI 1.19, 3.07) were more likely to be underweight than their counterparts. In conclusion, CaM consumption was associated with lower prevalence of stunting and underweight than BM. Promoting CaM in pastoralist areas may help to curb the high level of undernutrition.

Key words: Bovine milk: Camel milk: Growth failures: Pre-schoolers

\section{Introduction}

Undernutrition is a major global health problem with estimates in 2017 of 821 million undernourished people ${ }^{(1)}$. Based on 2017 estimates of undernutrition among children aged $<5$ years, 151 million were stunted and 50 million were wasted ${ }^{(1)}$. Accordingly, nutrition-related factors, especially undernutrition, contributed to approximately $45 \%$ of deaths in children aged $<5$ years. In sub-Saharan Africa (SSA), $<5$ years old child death remains the highest in the world ${ }^{(2)}$, and estimates in 2017 were that globally 15000 children aged <5 years died every day ${ }^{(3)}$. Ethiopia was among the top five countries for a total number of $<5$ years old child deaths in 2018,

Abbreviations: AOR: adjusted odds ratio; BM: bovine milk; CaM: camel milk; CI: confidence interval, Hb, haemoglobin; SSA, sub-Saharan Afric; UNICEF, United Nations Children's Fund; VIF, variance inflation factor ; WHO: World Health Organization

* Corresponding author: Anbissa Muleta, email anbissa.zg4@gmail.com 
according to a UNICEF report ${ }^{(4)}$. Moreover, the rates of all types of growth failure (i.e. stunting, wasting and underweight) in Ethiopia remain a public health concern ${ }^{(5)}$. The Ethiopian Somali region has lower stunting and relatively higher underweight and wasting compared with other regional states of Ethiopia ${ }^{(5,6)}$.

Childhood undernutrition has developmental, economic, social and medical impacts which are serious and lasting, for individuals and their families, for communities and countries ${ }^{(7)}$. Furthermore, lower academic performance in school and cognitive deficit and poor economic development in adulthood are associated with childhood undernutrition ${ }^{(8)}$. An immediate cause of childhood undernutrition is an inadequate intake of nutritious food and a high burden of disease, with numerous underlying contributors. These include food insecurity, poor child feeding practices, lack of improved sanitation and lack of access to quality health and nutrition services, all of which are linked to socio-economic status and sociocultural contexts ${ }^{(8,9)}$.

In pastoral areas of Ethiopia, there has been a growing interest in milk production and consumption; consumers are looking for foodstuffs containing milk and milk products as important contributors to a healthy and balanced diet for children ${ }^{(10,11)}$. Cow and camel milk (CaM) are the most often consumed milk types for infants and young children; other types such as goat and sheep milk are consumed very rarely by children ${ }^{(12,13)}$. However, the price of unpasteurised and pasteurised milk is relatively expensive in Somali and Afar regions of Ethiopia as compared with other regional states because of greater demand and more extensive use of milk in their meals ${ }^{(14,15)}$.

In Ethiopian pastoral Somalis, cereal and cereal products are common in children's diets ${ }^{(15)}$. Moreover, milk is a staple of the traditional diet of Somali pastoralist children. The milk is obtained from either bovine (BM) or camel (CaM), but CaM is the preferred product that can be used fresh (ma'an), slightly sour (suusa) or sour (garoor) ${ }^{(13)}$. According to a 2010/11 report, Ethiopia produces about 4 billion litres of milk per year where $83 \%$ is $\mathrm{BM}$ followed by $17 \%$ from $\mathrm{CaM}^{(16)}$, but per capita consumption is very low, estimated at about 20 litres. CaM can supply required nutrients for child nutrition and eliminate the allergy complications sometimes caused by certain protein fractions in $\mathrm{BM}^{(17)}$. The composition of CaM vs. $\mathrm{BM}$ (in $\mathrm{g} /$ $100 \mathrm{~mL})$ includes: protein $(3 \cdot 1$ vs. $3 \cdot 5)$, fat $(3.5$ vs. $3 \cdot 5)$, ash $(0.79$ vs. 0.76$)$ and total solid (11.9 vs. 12.5$)$, calcium (114 vs. $115 \mathrm{mg} / 100 \mathrm{~mL})$ and iron $(0.30 v$ s. $0.04 \mathrm{mg} / 100 \mathrm{~mL})$.

Furthermore, compared with BM, CaM lacks $\beta$-lactoglobulin. However, CaM contains lactoferrin, a protein also found in human breast milk ${ }^{(18-20)}$. These milk nutrients have potential to contribute in explicit ways to the growth process and linear growth of children ${ }^{(19)}$.

According to several studies, CaM is different from BM in its composition and also has nutraceutical properties. Nutraceuticals found in CaM include insulin-like peptides, lysozymes, lactoferrin and antioxidative vitamins ${ }^{(20,21)}$ with antidiabetic, hypoallergenic, antihypertensive, anticancer and antimicrobial effects with substantial benefits for human health as a functional food ${ }^{(17,20,22,23)}$. To date, there are several studies conducted on BM consumption and childhood undernutrition in developed and developing countries ${ }^{(24)}$; however, to our understanding, there is a gap regarding the associations between $\mathrm{CaM}$ or $\mathrm{BM}$ consumption and growth failures in Ethiopia and elsewhere. Therefore, the main aim of the present study was to compare the prevalence of growth failures between CaM and BM consumers. Secondly, we investigated associations between $\mathrm{CaM}$ or $\mathrm{BM}$ consumption and other predictors of growth failures in rural pastoral districts of Somali, Ethiopia.

\section{Methods and materials}

\section{Study design, setting and sampling}

A community-based comparative cross-sectional study was carried out among 388 pre-schoolers, aged 24-59 months from November to December 2018. For the present study, two pastoral districts, namely Degahabour and Harorays, were randomly selected from high camel and cattle population districts, respectively.

The sample size required for the study was estimated to be 369 children by using a single population proportion formula based on $60 \%$ anaemia among $<5$ years old children in a previous study ${ }^{(25)}, 95 \%$ confidence level and $5 \%$ margin of error. Adding $10 \%$ non-response rate, the final sample size was 406 including both CaM- and BM-consuming preschoolers. The sample was equally allocated to the two strata by the source of milk being consumed by children.

A multistage sampling technique was employed. The districts were selected randomly from those with camel or cattle populations. Then the study kebeles (smallest administrative units) were selected randomly from each district. Households in each kebele were stratified by the source of milk given to their children (CaM vs. BM). The presence of a lactating camel or lactating cow in the household was obtained from health extension workers and was taken as a marker to stratify the households. From each stratum, a child aged 24-59 months was selected randomly at each household. If more than one eligible child was present in the household, a child was selected by the lottery method. Researchers were not blind to the source of milk consumed by the child, because interviews and measurements were done at the household level.

\section{Data collection}

Socio-demographic, economic, water, sanitation and hygiene, as well as milk feeding practices, were collected by individual interviews of mothers by trained data collectors fluent in Af-Somali and English. The questionnaire was pre-tested in kebeles other than the study kebeles before the data collection. Additionally, mothers were asked if their child had consumed food from a list of seven food groups on the previous day from the time that the child awakened until the child slept. The food groups were (i) cereals, tubers or roots; (ii) meat, poultry and fish (flesh foods); (iii) milk and dairy products; (iv) eggs; (v) nuts/legumes; (vi) vitamin A-rich fruits or vegetables; (vii) other fruits and vegetables. These seven categories are among the food groups suggested for evaluating diets of children $^{(26)}$. 


\section{Blood biochemical assessments}

A finger prick blood sample was collected from each child according to WHO guidelines ${ }^{(27)}$. Haemoglobin $(\mathrm{Hb})$ concentration was measured using HemoCue (Hb 301 model) with regular calibration following manufacturer's instructions (HemoCue Ltd, Sheffield, UK). A child with an $\mathrm{Hb}$ value of $<11 \mathrm{~g} / \mathrm{dLwas}$ considered as anaemic ${ }^{(28)}$. The use of the HemoCue has been validated in field studies, and the coefficient of variation has been reported as $3.9 \%{ }^{(29)}$. All children diagnosed with anaemia were immediately referred to local health facilities for further treatment.

\section{Anthropometric measurements}

The researcher and assistant conducted anthropometric measurements of each child at home. The height and weight measures were taken twice with bare feet and light clothes following standard procedures. Child age was obtained from a parental recall using an events calendar. Body weight was measured with a SECA Model 874 electronic digital weighing scale (Seca GmbH \& Co KG, Hamburg, Germany) to the nearest $0.1 \mathrm{~kg}$. The scale was calibrated at least twice a day against a standard weight. The height was measured in an erect position to the nearest $0.1 \mathrm{~cm}$ using a calibrated portable SECA stadiometer (Seca GmbH \& Co KG, Hamburg, Germany). During measurement of the height, the head was positioned at the Frankfurt plane and the four body parts (heel, calf, buttocks and shoulder) touched the vertical stand of the stadiometer. Using the WHO growth standards ${ }^{(30)}$, weight-for-age, height-for-age and weight-for-height $z$-scores were determined using WHO Anthro version 3.1.0 $0^{(31)}$ for children aged $<5$ years.

\section{Data analysis}

Frequency distributions and confidence intervals (CIs) were calculated for child and household characteristics. Additionally, frequencies for these characteristics were calculated based on the type of milk consumed. Furthermore, frequencies for food group consumption and anthropometric indices also were calculated for the group as a whole as well as based on the type of milk consumed. Pearson's $\chi^{2}$ test was used to determine associations with the background characteristics, food group consumption and milk source. Independent sample $t$-tests identified significant differences in each of the anthropometric indices based on the type of milk consumed. For the analysis of factors predicting growth failure, the normality of continuous data was checked by the Kolmogorov-Smirnov test. The potential predictors for anthropometric measurements were identified by bivariate analysis with $P<0.05$ for inclusion in the multivariable analysis model. Multicollinearity was checked using the variance inflation factor (VIF) statistic, with VIF $>10$ as the indication of multicollinearity for the logistic regression model. A forward Wald stepwise model was developed, and odds ratios were used to evaluate factors associated with child growth. All statistical analyses were performed with SPSS version 20 (IBM, Armonk, NY, USA), and statistical significance was reported at $P<0 \cdot 05$.

\section{Results}

The mean (SD) age of the children was 38.5 (10.2) months. Slightly more than half of the study participants were boys. About two-thirds of children were fed breast milk beyond 2 years and more than nine in ten children were ever breastfed. Moreover, more than half of pre-schoolers consumed milk $\geq 4$ times/week (Table 1).

Almost all mothers of the pre-schoolers had never attended school, more than three-fourths were self-employed/homeworkers and $60.6 \%$ had greater than or equal to seven persons in a household. About $61.7 \%$ of children were living in households with no toilet/latrine, $44.3 \%$ drank unsafe/ unimproved water and $8.8 \%$ drank untreated water. Moreover, nearly one-fourth of mothers never washed their hands after defaecation or before cooking and breastfeeding.

Substantially more than half of children in both CaM and BM strata were fed breast milk beyond 2 years of age. A higher proportion of BM consumers had milk four or more times in a week period than did CaM consumers. In total, $75 \%$ of $\mathrm{BM}$ consumers but fewer than $45 \%$ of $\mathrm{CaM}$-consuming children were anaemic as presented in Table 1 .

We also found that a significantly higher proportion of preschoolers who consumed either $\mathrm{CaM}$ or BM used modern health facilities than traditional health facilities. More children who consumed $\mathrm{CaM}$ than $\mathrm{BM}$ reported health problems in the last 2 weeks; however, more CaM-consuming children reported safe/improved water sources in the household than did BM-consuming children.

\section{Food group patterns among children consuming CaM and BM}

In the present study, the major food sources for children in the pastoral districts were dairy products and grains, roots and tubers (Table 2). Very few $(0.8 \%)$ pre-schoolers consumed eggs, $16.5 \%$ consumed flesh foods, $16 \cdot 8 \%$ consumed other fruits and vegetables and $22.4 \%$ consumed vitamin A-rich fruits and vegetables. Only three $\mathrm{CaM}$ consumers and no $\mathrm{BM}$-consuming pre-school children ate eggs in the present study. In addition, both CaM- and BM-consuming pre-school children had in general low flesh foods (i.e. meat, fish, poultry and liver/organ meat) and other fruits and vegetables. However, CaM-consuming children had significantly lower flesh foods and higher other fruit and vegetable intakes as compared with BM-consuming children in the $24 \mathrm{~h}$ preceding the day of our interview as presented in Table 2.

\section{Anthropometric measures by milk source}

Stunting, underweight and wasting prevalence in the rural districts of Somali are presented overall and by $\mathrm{CaM}$ or BM consumption strata in Table 3. Overall, $24.1 \%$ (95 \% CI 20.5, $28.3)$ of pre-schoolers were stunted, $34.8 \%$ (95\% CI 29.9, $39 \cdot 6$ ) were wasted and $34.7 \%$ (95\% CI 30.1, 39.9) were underweight. Moreover, a higher proportion of pre-schoolers consuming BM were stunted (72 vs. $28 \% ; P<0.001)$ and underweight $(70 \cdot 1$ vs. $29.9 \% ; P<0 \cdot 001)$ compared with $\mathrm{CaM}$ consumers. In contrast, the prevalence of wasting was 
Table 1. Percentage distribution of child and household characteristics among CaM- and BM-consuming pre-schoolers in Somali region, Ethiopia

\begin{tabular}{|c|c|c|c|c|c|}
\hline Variables & $n$ & $\begin{array}{c}\text { All } \\
N 386-388 \\
\%(95 \% \mathrm{Cl})\end{array}$ & $\begin{array}{l}\mathrm{CaM} \\
N 185 \\
n(\%)\end{array}$ & $\begin{array}{c}\text { BM } \\
N 203 \\
n(\%)\end{array}$ & $P$ \\
\hline \multicolumn{6}{|l|}{ Child characteristics } \\
\hline \multicolumn{6}{|l|}{ Sex } \\
\hline Boy & 198 & $51 \cdot 3(46 \cdot 1,56)$ & $95(51.4)$ & $103(50 \cdot 7)$ & \multirow[t]{2}{*}{0.90} \\
\hline Girl & 188 & $48.7(44,53.9)$ & $90(48 \cdot 6)$ & $100(49 \cdot 3)$ & \\
\hline \multicolumn{6}{|l|}{ Age (months) } \\
\hline $24-41$ & 243 & $62 \cdot 6(58 \cdot 0,67 \cdot 5)$ & $114(61 \cdot 6)$ & $129(63.5)$ & \multirow[t]{2}{*}{0.69} \\
\hline $41-59$ & 145 & $37.4(32 \cdot 5,42 \cdot 0)$ & $71(38.4)$ & $74(36.5)$ & \\
\hline \multicolumn{6}{|l|}{ Duration of breastfeeding } \\
\hline$<2$ years & 121 & $31 \cdot 3(27 \cdot 2,36 \cdot 0)$ & $68(36 \cdot 8)$ & $54(26 \cdot 6)$ & \multirow[t]{2}{*}{0.03} \\
\hline$\geq 2$ years & 265 & $68 \cdot 7(64 \cdot 0,72 \cdot 8)$ & $117(63 \cdot 2)$ & $149(73.4)$ & \\
\hline \multicolumn{6}{|l|}{ Breastfed ever } \\
\hline Yes & 368 & $95 \cdot 7(93 \cdot 3,97 \cdot 4)$ & $176(95 \cdot 1)$ & $194(95 \cdot 6)$ & \multirow[t]{2}{*}{0.84} \\
\hline No & 18 & $4 \cdot 3(2 \cdot 6,6 \cdot 7)$ & $9(4.9)$ & $9(4.4)$ & \\
\hline \multicolumn{6}{|l|}{ Milk consumption per week } \\
\hline $1-3$ & 184 & $47 \cdot 4(42 \cdot 5,52 \cdot 1)$ & $105(56 \cdot 8)$ & 79 (38.9) & \multirow[t]{2}{*}{$\leq 0.001$} \\
\hline$\geq 4$ & 204 & $52 \cdot 6(47 \cdot 9,57 \cdot 5)$ & $80(43 \cdot 2)$ & $124(61 \cdot 1)$ & \\
\hline \multicolumn{6}{|c|}{ Any child health problem in the last 2 weeks } \\
\hline Yes & 46 & $11.9(8 \cdot 8,15 \cdot 0)$ & $32(17.5)$ & $14(6 \cdot 9)$ & \multirow[t]{2}{*}{0.001} \\
\hline No & 340 & $88 \cdot 1(85 \cdot 0,91 \cdot 2)$ & $151(82 \cdot 5)$ & $189(93 \cdot 1)$ & \\
\hline \multicolumn{6}{|l|}{ Anaemia status } \\
\hline Anaemic & 232 & $59 \cdot 8(54 \cdot 9,64 \cdot 4)$ & $79(42 \cdot 7)$ & $153(75.4)$ & \multirow[t]{2}{*}{$\leq 0.001$} \\
\hline Non-anaemic & 156 & $40 \cdot 2(35 \cdot 6,45 \cdot 1)$ & $106(57 \cdot 3)$ & $50(24 \cdot 6)$ & \\
\hline \multirow{2}{*}{\multicolumn{6}{|c|}{$\begin{array}{l}\text { Household characteristics } \\
\text { Maternal educational status }\end{array}$}} \\
\hline & & & & & \\
\hline No schooling & 379 & $97.5(96 \cdot 1,99 \cdot 0)$ & $179(96 \cdot 8)$ & $200(98.5)$ & \multirow[t]{2}{*}{0.25} \\
\hline Attended school & 9 & $2.5(1.0,3.9)$ & $6(3 \cdot 2)$ & $3(1.5)$ & \\
\hline \multicolumn{6}{|l|}{ Maternal employment status } \\
\hline Self-employed/home-worker & 301 & $78.0(73.8,81.9)$ & $139(75 \cdot 1)$ & $164(80 \cdot 8)$ & 0.18 \\
\hline Labour/non-employed & 85 & $22 \cdot 0(18 \cdot 1,26 \cdot 2)$ & $46(24.9)$ & $39(19.2)$ & \\
\hline No. of children aged $<5$ years & & & & & \\
\hline $1-2$ & 300 & $77 \cdot 3(72 \cdot 9,81 \cdot 4)$ & $137(74 \cdot 1)$ & $163(80 \cdot 3)$ & 0.14 \\
\hline$>3$ & 88 & $22 \cdot 7(18 \cdot 6,27 \cdot 1)$ & $48(25.9)$ & $40(19.7)$ & \\
\hline Total family size & & & & & \\
\hline$\leq 6$ & 153 & $39.4(35 \cdot 1,44 \cdot 3)$ & $66(35 \cdot 7)$ & $87(42.9)$ & 0.15 \\
\hline$\geq 7$ & 235 & $60 \cdot 6(55 \cdot 7,64 \cdot 9)$ & $119(64 \cdot 3)$ & $116(57 \cdot 1)$ & \\
\hline Health care facility & & & & & \\
\hline Modern health facility & 327 & $84.7(80 \cdot 8,88 \cdot 1)$ & $169(91 \cdot 4)$ & $159(78 \cdot 3)$ & $\leq 0.001$ \\
\hline Traditional healers & 59 & $15 \cdot 3(11 \cdot 9,19 \cdot 2)$ & $16(8 \cdot 6)$ & $44(21 \cdot 7)$ & \\
\hline Drinking water source & & & & & \\
\hline Safe/improved & 215 & $55 \cdot 7(50 \cdot 5,60 \cdot 4)$ & $142(76 \cdot 8)$ & $74(36 \cdot 5)$ & $\leq 0.001$ \\
\hline Unsafe/unimproved & 171 & $44.3(39.6,49.5)$ & $43(23 \cdot 2)$ & $129(63.5)$ & \\
\hline Time spent to fetch water & & & & & \\
\hline Less than $1 \mathrm{~h}$ & 258 & $66 \cdot 8(62 \cdot 4,71 \cdot 8)$ & $103(55 \cdot 7)$ & $156(76 \cdot 8)$ & $\leq 0.001$ \\
\hline Greater than $1 \mathrm{~h}$ & 128 & $33 \cdot 2(28 \cdot 2,37 \cdot 6)$ & $82(44 \cdot 3)$ & $47(23 \cdot 2)$ & \\
\hline Water drink in the household & & & & & \\
\hline Untreated & 354 & $91 \cdot 2(88 \cdot 6,94)$ & $161(87.0)$ & $193(95 \cdot 1)$ & 0.005 \\
\hline Treated $^{\mathrm{a}}$ & 34 & $8 \cdot 8(6.0,11.4)$ & $24(13.0)$ & $10(4.9)$ & \\
\hline Waste disposal & & & & & \\
\hline Buried/compost/fertiliser & 296 & $76.5(72 \cdot 2,80 \cdot 9)$ & $139(75 \cdot 1)$ & $158(77 \cdot 8)$ & 0.53 \\
\hline Throw to roadside/farm & 92 & $23.5(19 \cdot 1,27 \cdot 8)$ & $46(24.9)$ & $45(22 \cdot 2)$ & \\
\hline Presence of toilet/latrine in hou & & & & & \\
\hline Yes & 148 & $38 \cdot 3(33 \cdot 7,43 \cdot 3)$ & $74(40 \cdot 0)$ & $74(36.5)$ & 0.47 \\
\hline No & 238 & $61 \cdot 7(56 \cdot 7,66 \cdot 3)$ & $111(60 \cdot 0)$ & $129(63.5)$ & \\
\hline Hand washing practice & & & & & \\
\hline Never wash & 96 & $24 \cdot 7(20 \cdot 6,29 \cdot 1)$ & $48(25.9)$ & $48(23 \cdot 6)$ & 0.60 \\
\hline Wash hands at key times ${ }^{b}$ & 292 & $75 \cdot 3(70 \cdot 9,79.4)$ & $137(74 \cdot 1)$ & $155(76.4)$ & \\
\hline
\end{tabular}

a Physically or chemically treated.

${ }^{\mathrm{b}}$ Wash hands after defaecation and cleaning child faeces or before cooking and breastfeeding.

more similar and not significantly different between BM and CaM consumers. In BM compared with CaM-consuming preschoolers, significantly higher severe stunting $(76 v$ s. $24 \% ; P=$ $0 \cdot 002)$, severe wasting $(66$ vs. $34 \% ; P=0.048)$ and severe underweight (78 vs. $22 \% ; P<0 \cdot 001)$ were observed.

\section{Factors predicting childhood undernutrition}

After adjusting with covariates in the multivariable logistic regression model, the odds of stunting were more likely to be higher among anaemic children [adjusted odds ratio (AOR): 4.22; $95 \%$ CI 2.23, 7.98], and children who 
Table 2. Food group consumption patterns of pre-schoolers aged 24-59 months in rural pastoral districts of Somali, Ethiopia

\begin{tabular}{|c|c|c|c|c|}
\hline Food group(s) & $\begin{array}{l}\text { All }(N \text { 388) } \\
n(\%)\end{array}$ & $\begin{array}{c}\mathrm{CaM}(N 185) \\
n(\%)\end{array}$ & $\begin{array}{c}\mathrm{BM}(N 203) \\
n(\%)\end{array}$ & $P$ \\
\hline \multicolumn{5}{|c|}{ Grains, roots and tubers } \\
\hline Yes & $385(99 \cdot 2)$ & $185(100)$ & $200(98.5)$ & 0.0 \\
\hline No & $3(0 \cdot 8)$ & 0 & $3(1.5)$ & \\
\hline \multicolumn{5}{|c|}{ Legumes and nuts } \\
\hline Yes & $156(40 \cdot 2)$ & $71(38.4)$ & $85(41.9)$ & 0.4 \\
\hline No & $232(59 \cdot 8)$ & $114(61 \cdot 6)$ & $118(58 \cdot 1)$ & \\
\hline \multicolumn{5}{|c|}{ Dairy products (milk, yoghurt and cheese) } \\
\hline Yes & $388(100)$ & $185(100)$ & $203(100)$ & \\
\hline \multicolumn{5}{|c|}{ Flesh foods (meat, fish, poultry and liver/organ meat) } \\
\hline Yes & $64(16.5)$ & $21(11.4)$ & $43(21 \cdot 2)$ & 0.0 \\
\hline No & $324(83.5)$ & $164(88.6)$ & $160(78 \cdot 8)$ & \\
\hline \multicolumn{5}{|l|}{ Eggs } \\
\hline Yes & $3(0.8)$ & $3(1 \cdot 6)$ & 0 & 0.07 \\
\hline No & $385(99 \cdot 2)$ & $182(98.4)$ & $203(100)$ & \\
\hline \multicolumn{5}{|c|}{ Vitamin A-rich fruits and vegetables } \\
\hline Yes & $87(22.4)$ & $45(24 \cdot 3)$ & $42(20 \cdot 7)$ & 0.39 \\
\hline No & $301(77 \cdot 6$ & $140(75 \cdot 7)$ & $161(79 \cdot 3)$ & \\
\hline \multicolumn{5}{|c|}{ Other fruits and vegetables } \\
\hline Yes & $65(16 \cdot 8)$ & $41(22 \cdot 2)$ & $24(11 \cdot 8)$ & 0.01 \\
\hline No & $323(83 \cdot 2)$ & $144(77 \cdot 8)$ & $178(88.2)$ & \\
\hline
\end{tabular}

consumed BM (AOR: 2.10; $95 \%$ CI 1.22, 3.61) compared with those children without anaemia and who consumed CaM. Being a girl reduced odds of stunting by $43 \%$ compared with boys (Table 4).

Similarly, the odds of underweight were more likely to be higher among anaemic children (AOR: 2.27; $95 \%$ CI 1.38, $3 \cdot 72$ ), children who consumed BM (AOR: 1.97; $95 \%$ CI $1 \cdot 20,3 \cdot 24)$ and who drank unsafe water (AOR: 1.91; $95 \%$ CI 1.19, 3.07) compared with children without anaemia who consumed $\mathrm{CaM}$ and drank safe water.

Wasting was significantly associated with drinking unsafe and untreated water in households $(P=0.003$ and $P=0.04)$, respectively. Drinking unsafe water (AOR: 1.93; $95 \%$ CI $1 \cdot 25,2.95)$ and drinking untreated water (AOR: 2.77; $95 \%$ CI $1.03,7.44$ ) in the household increased odds of wasting by nearly twice and more than twice, respectively, compared with those who drank safe and treated water.

\section{Discussion}

The overall growth failure of pre-schoolers was high in the present study with $24.1 \%$ of pre-schoolers being stunted, $34.8 \%$ were wasted and $34.7 \%$ were underweight. Stunting was less than the national figure (38\%), while wasting and underweight were higher than the national rates of 10 and $24 \%{ }^{(5)}$, respectively. A higher prevalence of stunting was reported in some parts of Ethiopia such as Amhara ${ }^{(32)}$, Bule Hora district ${ }^{(33)}$ and Belesa district of northwest Ethiopia ${ }^{(34)}$ which ranged from 27.6 to $57.7 \%$; these higher numbers might suggest poor child care practices and lack of access to health facilities ${ }^{(35)}$. However, a lower prevalence of stunting was observed in Gambia (15.7\%) and Wolayta-Sodo, Southern Ethiopia (22.2 $\%)$ as compared with our present result ${ }^{(36,37)}$.

In the present study, wasting was threefold higher compared with several results reported in other parts of Ethiopia such as Amhara, Bule Hora district, Wolayta-Sodo, Southern Ethiopia, Belesa district, northwest Ethiopia and in Gambia ${ }^{(32-34,36,37)}$ that ranged from 5.5 to $16 \%$. Similarly, lower childhood underweight was reported as compared with the present study in several studies ${ }^{(32,36,38)}$. On the other hand, higher childhood underweight was found in a study in India ${ }^{(39)}$.

Milk is known to provide essential nutrients for growth during childhood, but available nutrients differ by milk sources. $\mathrm{CaM}$ has positive nutritional and health benefits compared with $\mathrm{BM}$ because of its easy digestion and absorption for children ${ }^{(20,40)}$. In our present study, children who consumed BM were more vulnerable to stunting and underweight as compared with CaM consumers. Several studies and reviews report that $\mathrm{CaM}$ has antimicrobial and antiparasitic factors as well as inflammation inhibitors that have beneficial effects to reduce childhood stunting and underweight ${ }^{(21,22,40)}$. Moreover, CaM has potential to reduce nutrition-related iron deficiency anaemia by providing ten times higher concentrations of iron and five times higher vitamin $\mathrm{C}$ as compared with $\mathrm{BM}^{(20)}$ which could contribute to the reduction of childhood stunting and underweight. Furthermore, CaM has higher concentrations of insulin-like growth factor-1 and growthpromoting nutrients like zinc and niacin relative to $\mathrm{BM}^{(41)}$.

Table 3. Pre-school children aged 24-59 months - anthropometric measures by milk source in rural pastoral districts of Somali, Ethiopia

\begin{tabular}{|c|c|c|c|c|c|c|c|c|}
\hline \multirow[b]{2}{*}{ Characteristics } & \multicolumn{3}{|c|}{ All } & \multicolumn{2}{|c|}{ CaM } & \multicolumn{2}{|r|}{ BM } & \multirow[b]{2}{*}{$P$} \\
\hline & $N$ & Mean/\% & $95 \% \mathrm{Cl}$ & $N$ & Mean/\% & $N$ & Mean/\% & \\
\hline \multicolumn{9}{|l|}{ Stunting } \\
\hline HAZ, mean (SD) & 386 & $-0.81(1.73)$ & $-0.99,-0.64$ & 184 & $-0.36(0.12)$ & 202 & $-1.22(1.64)$ & $<0.001$ \\
\hline Any stunting & 93 & $24 \cdot 1$ & $20 \cdot 5,28 \cdot 3$ & 26 & $28 \cdot 0$ & 67 & $72 \cdot 0$ & $<0.001$ \\
\hline Severe stunting & 38 & $9 \cdot 8$ & $7 \cdot 3,12 \cdot 5$ & 9 & 23.7 & 29 & $76 \cdot 3$ & 0.002 \\
\hline \multicolumn{9}{|l|}{ Wasting } \\
\hline WHZ, mean (SD) & 385 & $-1.50(1.48)$ & $-1 \cdot 65,-1 \cdot 36$ & 183 & $-1.37(1.47)$ & 202 & $-1.63(1.49)$ & 0.086 \\
\hline Any wasting & 134 & $34 \cdot 8$ & $29 \cdot 9,39 \cdot 6$ & 58 & 43.3 & 76 & $56 \cdot 7$ & 0.223 \\
\hline Severe wasting & 47 & $12 \cdot 2$ & $9 \cdot 4,15 \cdot 1$ & 16 & $34 \cdot 0$ & 31 & $66 \cdot 0$ & 0.048 \\
\hline \multicolumn{9}{|l|}{ Underweight } \\
\hline WAZ, mean (SD) & 386 & $-1.47(1.28)$ & $-1.59,-1.34$ & 184 & $-1 \cdot 12(1 \cdot 15)$ & 202 & $-1 \cdot 79(1.30)$ & $<0.001$ \\
\hline Any underweight & 134 & 34.7 & $30 \cdot 1,39 \cdot 9$ & 40 & 29.9 & 94 & $70 \cdot 1$ & $<0.001$ \\
\hline Severe underweight & 54 & $14 \cdot 0$ & $10.9,17.9$ & 12 & $22 \cdot 2$ & 42 & $77 \cdot 8$ & $<0.001$ \\
\hline
\end{tabular}

Note: $\mathrm{Cl}$; confidence interval; severe stunting: height-for-age $z$-score $(\mathrm{HAZ})<-3 \mathrm{SD}$; any stunting: $\mathrm{HAZ}<-2 \mathrm{SD}$; severe underweight: weight-for-age $Z$-score $(\mathrm{WAZ})<-3 \mathrm{SD}$; any underweight: $W A Z<-2 \mathrm{SD}$; severe wasting: weight-for-height $z$-score $(\mathrm{WHZ})<-3 \mathrm{SD}$; any wasting: $\mathrm{WHZ}<-2 \mathrm{SD}$. 
Table 4. Factors associated with stunting, wasting and underweight in rural pastoral districts of Somali, Ethiopia

\begin{tabular}{|c|c|c|c|c|}
\hline Characteristics & Predictor category & AOR & $95 \% \mathrm{Cl}$ & $P$ \\
\hline \multicolumn{5}{|l|}{ Stunting ${ }^{a}$} \\
\hline \multicolumn{5}{|c|}{ Factors remaining in the model } \\
\hline Anaemia status & Anaemic & $4 \cdot 22$ & $2 \cdot 23,7.98$ & $\leq 0.0001$ \\
\hline Sex of child & Girl & 0.57 & $0.34,0.94$ & 0.03 \\
\hline Milk source consumed & BM & $2 \cdot 10$ & $1.22,3.61$ & 0.007 \\
\hline \multicolumn{5}{|l|}{ Underweight ${ }^{\mathrm{b}}$} \\
\hline \multicolumn{5}{|c|}{ Factors remaining in the model } \\
\hline Milk source consumed & BM & 1.97 & $1 \cdot 20,3 \cdot 24$ & 0.008 \\
\hline Anaemia status & Anaemic & $2 \cdot 27$ & $1.38,3.72$ & 0.001 \\
\hline Drinking water source & Unsafe/unimproved water & 1.91 & $1.19,3.07$ & 0.007 \\
\hline \multicolumn{5}{|l|}{ Wasting $^{\mathrm{c}}$} \\
\hline \multicolumn{5}{|c|}{ Factors remaining in the model } \\
\hline Drinking water source & Unsafe/unimproved water & 1.93 & $1.25,2.97$ & 0.003 \\
\hline Water treatment used & Untreated & 2.77 & $1.03,7.44$ & 0.04 \\
\hline
\end{tabular}

In general milk consumption in childhood has long been assumed to be positively associated with growth. This association may be due to the nutritious content of milk such as high levels of proteins and micro- and macronutrients as well as high calcium and the insulin-like growth factor-1 that are of major relevance for children's development and growth ${ }^{(11,19)}$. In the present study, more than half of pre-schoolers consumed milk more than four times in a week which might support childhood growth. However, a significantly lower proportion of CaM-consuming pre-schoolers had milk $\geq 4$ times/week compared with BM consumers. This might be an explanation for the higher intakes of the other fruit and vegetable food groups by the CaM consumers than BM consumers as presented in Table 2 of the present study.

Our present study showed that $9.8 \%$ of pre-schoolers were severely stunted, $12 \cdot 2 \%$ were severely wasted and $14 \cdot 0 \%$ were severely underweight. The children who consumed CaM had a lower proportion of severe stunting, wasting and underweight than BM consumers. CaM's effect on the reduction of infections caused by parasites and pathogenic microorganisms could have contributed to these differences ${ }^{(22,42,43)}$

Our present results showed that boy pre-schoolers were more stunted than girls. Sex differences in pre-school children's height status also have been reported in low-income countries such as Guatemala, Senegal and various SSA countries ${ }^{(4-46)}$. Perhaps boys are more vulnerable to health inequalities than their girl counterparts in the same age groups ${ }^{(45)}$. The study finding was also consistent with previous research that reported boy children were more vulnerable to stunting because they required comparatively more calories for growth and development ${ }^{(8,47,48)}$. One of the reasons for low caloric intake in children might be low socio-economic status, based on findings in Pakistan and SSA ${ }^{(8,48)}$. Similarly, a study conducted in Guatemalan indigenous children showing that boys required greater energy intakes than girls could also make them more likely to be vulnerable for stunting with low socio-economic status ${ }^{(46)}$.
The odds of childhood stunting significantly increased with anaemia as compared with non-anaemic children. The likelihood of increased childhood stunting due to anaemia is consistent with several studies from low- and middle-income countries such as Ethiopia, Gambia, Guinea and China ${ }^{(36,49-51)}$. Anaemia may lead to increased susceptibility to childhood stunting by decreasing food intake, and thus inadequate satisfaction of required iron from the diet might have negative impacts on children's growth ${ }^{(52,53)}$. Additionally, the risk of underweight was significantly higher among anaemic children compared with non-anaemic. This result was consistent with previous findings that showed an increase in underweight in children with anaemia ${ }^{(54)}$ and, thus, may be associated with poor intake of family food rich in iron and loss of appetite because of anaemia infection ${ }^{(50)}$.

The odds of childhood stunting and underweight significantly increased in BM-consuming as compared with CaM-consuming pre-schoolers. To our understanding, there has not been a comparative study of the effects of BM and CaM consumption on child growth, but some studies have shown that milk consumption could contribute to anaemia and stunting in young children ${ }^{(50,55)}$. However, reports have indicated that $\mathrm{CaM}$ has unique potential for nutraceutical and therapeutic activities against different conditions such as anaemia, parasitic infections and milk protein allergies related to $\beta$-lactalbumin as compared with $\mathrm{BM}^{(17,21,40,41,56-59)}$ that could reduce stunting and underweight among the pastoralist children. Additionally, CaM has been fed as a human milk substitute in some studies ${ }^{(20)}$ and has had antimicrobial effects ${ }^{(42,60)}$.

For pre-schoolers in the present study, the odds of being wasted or underweight were between two and three times higher among children who drank unsafe/unimproved/ untreated water in their household. A systematic review of studies in SSA and a report based on Demographic Health Survey data in Guinea found similar results ${ }^{(8,49)}$ regardless of the milk type to be consumed by pre-schoolers. Unsafe and unimproved water is not free of pathogens and these could 
contribute to childhood illness, wasting and underweight. In sustainable development goal 2030, target $6 \cdot 1$ aims to ensure universal and equitable access to safe and affordable drinking water for all ${ }^{(61)}$; however, adequate safe and improved water sources for Somali rural pastoralist children remain limited and are immense challenges putting them at risk of loss of nutrients due to diarrheal diseases and contribute childhood undernutrition.

Among limitations, cross-sectional data were used for our present study analyses; thus, temporal relationships could not be characterised in the pathways from milk intake to child growth. Also, we could not differentiate causal relations on the outcomes. We did not demonstrate a mechanism by which CaM improved child growth compared with BM, but presented fact-based evidence about characteristics of CaM. We have not collected detailed child infection information. We suggest further characterisation of $\mathrm{CaM}$ and evaluation of its impact on the health and growth of children with welldesigned clinical trials.

\section{Conclusion}

Lower prevalence of stunting and underweight were observed among CaM-consuming compared with BM-consuming preschoolers. Severe growth failures of all types persisted among BM consumers. Both milk type and anaemia status predicted childhood stunting and underweight. Drinking water sources were significant predictors of both wasting and underweight of pre-schoolers. Being girls significantly reduced the odds of childhood stunting. Promoting CaM consumption for pre-schoolers in pastoralist and agro-pastoralist areas may be helpful to curb the high rates of undernutrition in the Somali region.

\section{Acknowledgments}

We are highly delighted to acknowledge each rural district health office administrator and local leaders who allowed the study to be conducted. We also thank Degahabour and Jigjiga University Referral Hospitals for providing their laboratories. We also acknowledge Jigiga and the Ministry of Science and Higher Education for their funding. Moreover, we highly appreciate caregivers/mothers who agreed to participate in the present study and also the data collectors.

A.M. conceived the study, developed the tool, coordinated the data collection activity, carried out the statistical analysis and drafted the manuscript. T.B., B.J.S. and D.H. were involved in statistical analysis, reviewing and editing the manuscript and guiding the study. All authors read and approved the final manuscript.

The present study was funded by the Ministry of Science and Higher Education and Jigiga University. The funding organisations were not involved in the design, data collection, analysis and interpretation of the study.

Ethical approval was obtained from the Institutional Review Board of the College of Medicine and Health Sciences, Hawassa University (Ref. No. IRB/137/10, dated 12 February 2018). Permission to collect data in Degahabour and Haroreys districts was obtained from the respective health bureaus. Oral and written consent was obtained from the mother for each child participating in the study after the research purpose and objectives were explained. The mothers were told to withdraw whenever they wished to stop participation during the data collection.

The authors declare that they have no competing interests.

\section{References}

1. FAO, IFAD, UNICEF, WFP, WHO (2018) The State of Food Security and Nutrition in the World 2018: Building Climate Resilience for Food Security and Nutrition. Rome, Italy: FAO.

2. Black RE, Victora CG, Walker SP, et al. (2013) Maternal and child undernutrition and overweight in low-income and middle-income countries. Lancet 382, 427-451.

3. UNIGME (2017) Levels and Trends in Child Mortality: Report 2017, Estimates Developed by the UN Inter-agency Group for Child Mortality Estimation. New Work: United Nations Children's Fund.

4. UNICEF (2019) The state of the world's children 2019. In Children, Food and Nutrition: Growing Well in a Changing World, pp. 1-258 [B Keeley, JD de Oliveira, E Zuehlke, G Sclama, K Vrolijk, U Young, D Ghebremichael \& D Anthony Eds. ]. New York: UNICEF.

5. Central Statistical Agency (CSA) Ethiopia and ICF (2016) Ethiopia Demographic and Health Survey 2016: Key Indicators Report. Addis Ababa, Ethiopia: CSA and ICF.

6. Tekile AK, Woya AA \& Basha GW (2019) Prevalence of malnutrition and associated factors among under-five children in Ethiopia: evidence from the 2016 Ethiopia Demographic and Health Survey. BMC Res Notes 12, 1-6.

7. WHO (2017) The Double Burden of Malnutrition: Policy Brief. Geneva, Switzerland.

8. Akombi BJ, Agho KE, Hall JJ, et al. (2017) Stunting, wasting and underweight in sub-Saharan Africa: a systematic review. Int $J$ Environ Res Public Health 14, 1-18.

9. Vaivada T, Gaffey MF, Das JK, et al. (2017) Evidence-based interventions for improvement of maternal and child nutrition in low-income settings: what's new? Curr Opin Clin Nutr Metab Care 20, 204-210.

10. Sadler K \& Catley A (2009) Milk Matters: The Role and Value of Mille in the Diets of Somali Pastoralist Children in Liben and Sbinile, Etbiopia. Addis Ababa, Ethiopia: Feinstein International Center, Tufts University and Save the Children.

11. Pereira PC (2014) Milk nutritional composition and its role in human health. Nutrition 30, 619-627.

12. Elhadi YA, Nyariki DM \& Wasonga O (2015) Role of camel milk in pastoral livelihoods in Kenya: contribution to household diet and income. Pastoralism 5, 2-8.

13. Guliye AY, Noor IM, Bebe BO, et al. (2007) Role of camels (Camelus dromedarius) in the traditional lifestyle of Somali pastoralists in northern Kenya. Outlook Agric 36, 29-34.

14. Ethiopian Public Health Institute (2013) Ethiopian National Food Consumption Survey. Addis Ababa, Ethiopia: Ethiopian Public Health Institute.

15. Fantu B, Bart M \& Feiruz Y (2017) The Rising Costs of Animal-Source Foods in Ethiopia: Evidence and Implications. Addis Ababa, Ethiopia. http://www.ifpri.org/publication/rising-costs-animal-source-foodsethiopia-evidence-implications.

16. Ministry of Agriculture and ILRI (2013) Dairy Value Chain Vision and Strategy for Ethiopia. Addis Ababa, Ethiopia: Ministry of Agriculture and ILRI.

17. Khatoon H \& Najam R (2017) Bioactive components in camel milk. In Milk as a Functional Food from Nonbovine Sources, pp. 377387 [H Khatoon \& R Najam Eds.]. Academic Press. Available at https:/doi.org/10.1016/B978-0-12-809762-5.00029-2.

18. Al Haji OA \& Al Kanhal HA (2010) Compositional, technological and nutritional aspects of dromedary camel milk. Int Dairy J 20, 811-821. 
19. Hoppe C, Mølgaard C \& Michaelsen KF (2006) Cow's milk and linear growth in industrialized and developing countries. Annu Rev Nutr 26, 131-173.

20. Alavi F, Salami M, Emam-Djomeh Z, et al. (2017) Nutraceutical properties of camel milk. In Milk as a Functional Food from Nonbovine Sources, pp. 451-468 [F Alavi, M Salami, Z EmamDjomeh \& M Mohammadian Eds.]. Elsevier Inc. Available at https://doi.10.1016/B978-0-12-809762-5.00036-x.

21. Dubey US, Lal M, Mittal A, et al. (2016) Therapeutic potential of camel milk. Emirates J Food Agric 28, 164-176.

22. Abdel Gader AGM \& Alhaider AA (2016) The unique medicinal properties of camel products: a review of the scientific evidence. J Taibah Univ Med Sci 11, 98-103.

23. Khalesi M, Salami M, Moslehishad M, et al. (2017) Biomolecular content of camel milk: a traditional superfood towards future healthcare industry. Trends Food Sci Technol 62, 49-58.

24. Grenov B \& Michaelsen KF (2018) Growth components of cow's milk: emphasis on effects in undernourished children. Food Nutr Bull 39, S45-S53.

25. Ethiopian Public Health Institute (2016) Ethiopian National Micronutrient Survey Report. Addis Ababa, Ethiopia: Ethiopian Public Health Institute.

26. Swindale A \& Bilinsky P (2006) Household Dietary Diversity Score for Measurement of Household Food Access: Indicator Guide (v.2). Washington, DC: FHI 360/FANTA.

27. WHO (2010) WHO Guidelines on Drawing Blood: Best Practices in Phlebotomy. Geneva, Switzerland.

28. WHO \& CDC (2005) Assessing the Iron Status of Populations. Geneva, Switzerland: WHO.

29. Neufeld L, García-Guerra A, Sánchez-Francia D, et al. (2002) Hemoglobin measured by Hemocue and a reference method in venous and capillary blood. Salud Publica de Mexico 44, 219-227.

30. WHO (2006) WHO Child Growth Standards: Length/Height-for-Age, Weight-for-Age, Weight-for-Length, Weight-for-Height and Body Mass Index-for-Age: Methods and Development. Geneva, Switzerland: World Health Organization.

31. WHO (2010) WHO Anthro for Personal Computer Manual: Software for Assessing Growth and Development of the World's Children. Geneva, World Health Organization.

32. Gashu D, Stoecker BJ, Bougma K, et al. (2016) Stunting, selenium deficiency and anemia are associated with poor cognitive performance in preschool children from rural Ethiopia. Nutr J 15, 1-8.

33. Asfaw M, Wondaferash M, Taha M, et al. (2015) Prevalence of undernutrition and associated factors among children aged between six to fifty nine months in Bule Hora district, South Ethiopia. BMC Public Health 15, 1-9.

34. Fentahun W, Wubshet M \& Tariku A (2016) Undernutrition and associated factors among children aged 6-59 months in east Belesa district, northwest Ethiopia: a community based crosssectional study. BMC Public Health 16, 1-10.

35. Rohner F, Northrop-clewes C, Tschannen AB, et al. (2013) Prevalence and public health relevance of micronutrient deficiencies and undernutrition in pre-school children and women of reproductive age in $\mathrm{Co}^{\wedge}$ te d'Ivoire, West Africa. Public Health Nutr 15, 1-13.

36. Petry N, Jallow B, Sawo Y, et al. (2019) Micronutrient deficiencies, nutritional status and the determinants of anemia in children 0-59 months of age and non-pregnant women of reproductive age in the Gambia. Nutrients 11, 1-20.

37. Eshete H, Abebe Y, Loha E, et al. (2017) Nutritional status and effect of maternal employment among children aged 6-59 months in Wolayta Sodo town, southern Ethiopia: a cross-sectional study. Ethiop J Health Sci 27, 155-162.

38. Abdulahi A, Shab-Bidar S, Rezaei S, et al. (2017) Nutritional status of under five children in Ethiopia: a systematic review and meta-analysis. Ethiop J Health Sci 27, 175-188.

39. Panda S, Sadhu C, Pramanik G, et al. (2017) Concerning public health situation of undernutrition in children and anemia in women in Indian Sundarbans delta: a community based crosssectional investigation. BMC Nutr 2, 1-10.
40. Singh R, Mal G \& Kumar D (2017) Camel milk: an important natural adjuvant. Agric Res 6, 327-340.

41. El-Hatmi H, Jrad Z, Salhi I, et al. (2015) Comparison of composition and whey protein fractions of human, camel, donkey, goat and cow milk. Mljekarstvo 65, 159-167.

42. Ennani B \& Hidane K (2004) Antimicrobial activity of camel's milk against pathogenic strains of Escherichia coli and Listeria monocytogenes. Int J Dairy Technol 57, 39-43.

43. Prabhurajeshwar C \& Chandrakanth K (2019) Evaluation of antimicrobial properties and their substances against pathogenic bacteria in-vitro by probiotic Lactobacilli strains isolated from commercial yoghurt. Clin Nutr Exp 23, 97-115.

44. Bork KA \& Diallo A (2017) Boys are more stunted than girls from early infancy to 3 years of age in rural Senegal. J Nutr 147, 940-947.

45. Wamani H, Åstrøm AN, Peterson S, et al. (2007) Boys are more stunted than girls in sub-Saharan Africa: a meta-analysis of 16 demographic and health surveys. BMC Pediatr 10,1-10.

46. Tumilowicz A, Habicht J, Pelto G, et al. (2015) Gender perceptions predict sex differences in growth patterns of indigenous Guatemalan infants and young children. Am J Clin Nutr 102, 1249-1258.

47. Demissie S (2013) Magnitude and factors associated with malnutrition in children 6-59 months of age in pastoral community of Dollo Ado district, Somali Region, Ethiopia. Sci J Public Health 1, 175-183.

48. Khan S, Zaheer S \& Safdar NF (2019) Determinants of stunting, underweight and wasting among children. BMC Public Health 19, $1-15$.

49. Woodruff BA, Wirth JP, Ngnie-teta I, et al. (2018) Determinants of stunting, wasting, and anemia in Guinean preschool age children: an analysis of DHS data from 1999, 2005, and 2012. Food Nutr Bull 39, 39-53.

50. Mohammed SH, Larijani B \& Esmaillzadeh A (2019) Concurrent anemia and stunting in young children: prevalence, dietary and nondietary associated factors. Nutr J 18, 1-10.

51. Yang W, Li X, Li Y, et al. (2012) Anemia, malnutrition and their correlations with socio-demographic characteristics and feeding practices among infants aged 0-18 months in rural areas of Shaanxi province in northwestern China: a cross-sectional study. BMC Public Health 12, 1-7.

52. Soliman AT, De Sanctis V \& Kalra S (2014) Anemia and growth. Indian J Endocrinol Metab 18, 1-6.

53. Sachdev HPS, Gera T \& Nestel P (2005) Effect of iron supplementation on physical growth in children: systematic review of randomised controlled trials. Public Health Nutr 9, 904-920.

54. Engidaye G, Melku M, Yalew A, et al. (2019) Undernutrition, maternal anemia and household food insecurity are risk factors of anemia among preschool aged children in Menz Gera midir district, eastern Amhara, Ethiopia: a community based cross-sectional study. BMC Public Health 19, 1-11.

55. Ziegler EE (2011) Consumption of cow's milk as a cause of iron deficiency in infants and toddlers. Nutr Rev 69, S37-S42.

56. Korish AA, Abdel Gader AGM \& Al Haider AA (2015) Camel milk ameliorates the coagulopathy in streptozotocin diabetic rat model. Int J Dairy Technol 68, 79-87.

57. Izadi A, Khedmat L \& Mojtahedi SY (2019) Nutritional and therapeutic perspectives of camel milk and its protein hydrolysates: a review on versatile biofunctional properties. J Funct Foods 60, 1-13.

58. Sboui A, Khorchani T, Djegham M, et al. (2010) Anti-diabetic effect of camel milk in alloxan-induced diabetic dogs: a dose-response experiment. J Anim Physiol Anim Nutr 94, 540-546.

59. Maryniak NZ, Hansen EB, Ballegaard ASR, et al. (2018) Comparison of the allergenicity and immunogenicity of camel and cow's milk—a study in brown Norway rats. Nutrients 10, 1-18.

60. Al-nabulsi AA, Olaimat AN, Osaili TM, et al. (2016) Behavior of Escherichia coli $\mathrm{O} 157: \mathrm{H} 7$ and Listeria monocytogenes during fermentation and storage of camel yogurt. J Dairy Sci 99, 1802-1811.

61. United Nations (2015) Transforming Our World: The 2030 Agenda for Sustainable Development 1-41. Available at https://sustainabledevelopment.un.org/content/documents/ (accessed 6 August 2020). 